\title{
Across-country genomic prediction of bull fertility in Jersey dairy cattle
}

\author{
Fernanda M. Rezende, ${ }^{1,2} \odot$ Mekonnen Haile-Mariam, ${ }^{3} \odot$ Jennie E. Pryce,,${ }^{3,4} \oplus$ and Francisco Peñagaricano ${ }^{1,5 *}$ (1) \\ ${ }^{1}$ Department of Animal Sciences, University of Florida, Gainesville 32611 \\ ${ }^{2}$ Faculdade de Medicina Veterinária, Universidade Federal de Uberlândia, Uberlândia MG 38410-337, Brazil \\ ${ }^{3}$ Agriculture Victoria Research, AgriBio, Centre for AgriBioscience, Bundoora, Victoria 3083, Australia \\ ${ }^{4}$ School of Applied Systems Biology, La Trobe University, Bundoora, Victoria 3083, Australia \\ ${ }^{5}$ Department of Animal and Dairy Sciences, University of Wisconsin-Madison, 53706
}

\section{ABSTRACT}

The use of information across populations is an attractive approach to increase the accuracy of genomic predictions for numerically small breeds and traits that are time-consuming and difficult to measure, such as male fertility in cattle. This study was conducted to evaluate genomic prediction of Jersey bull fertility using an across-country reference population combining records from the United States and Australia. The data set consisted of 1,570 US Jersey bulls with sire conception rate (SCR) records, 603 Australian Jersey bulls with semen fertility value (SFV) records and SNP genotypes for roughly 90,000 loci. Both SCR and SFV are evaluations of service sire fertility based on cow field data, and both are intended as phenotypic evaluations because the estimates include genetic and nongenetic effects. Within- and across-country genomic predictions were evaluated using univariate and bivariate genomic best linear unbiased prediction models. Predictive ability was assessed in 5-fold cross-validation using the correlation between observed and predicted fertility values and mean squared error of prediction. Within-country genomic predictions exhibited predictive correlations of around 0.28 and 0.02 for the United States and Australia, respectively. The Australian Jersey population is genetically diverse and small in size, so careful selection of the reference population by including only closely related animals (e.g., excluding New Zealand bulls, which is a less-related population) increased the predictive correlations up to 0.20 . Notably, the use of bivariate models fitting all US Jersey records and the optimized Australian population resulted in predictive correlations around of 0.24 for SFV values, which is a relative increase in predictive ability of $20 \%$. Conversely, for predicting SCR values, the use of an across-country reference population did not outperform the standard

Received May 15, 2020.

Accepted July 15, 2020 .

*Corresponding author: fpenagarican@wisc.edu approach using pure US Jersey reference data set. Our findings indicate that genomic prediction of male fertility in dairy cattle is feasible, and the use of an acrosscountry reference population would be beneficial when local populations are small and genetically diverse.

Key words: multicountry reference population, semen fertility value, sire conception rate

\section{INTRODUCTION}

Genomic prediction has been successfully implemented in livestock production, especially in dairy cattle. Its adoption in the US Holstein population has doubled the annual genetic gain for production traits and has increased from 3- to 4-fold for lowly heritable traits, including health and female fertility traits (Weller et al., 2017). The rate of genetic gain depends on the reliability of genomic estimated breeding values (GEBV), which in turn depends on the size of the reference population used to estimate the SNP effects (Daetwyler et al., 2008; Goddard, 2009; Hayes et al., 2009; VanRaden et al., 2009; Liu et al., 2011), and the genetic relationships between individuals in the reference population and selection candidates (Habier et al., 2010; Pszczola et al., 2012; Wientjes et al., 2013).

Assembling large enough reference populations for accurate prediction of GEBV is a major challenge, especially for numerically small breeds and for traits that are difficult or time-consuming to measure (Thomasen et al., 2014). Limited numbers of genotyped and phenotyped animals restrict the accuracy of genomic prediction. One approach to overcome this limitation has been to combine different populations either of the same breed or related breeds in the reference population, increasing the information available for the estimation of marker effects. Previous studies on simulated and real data have shown that genomic prediction combining different populations can work (de Roos et al., 2009; Brøndum et al., 2011; Lund et al., 2011; Zhou et al., 2014; Haile-Mariam et al., 2015; Su et al., 2016; Gebreyesus et al., 2019). However, the benefits of combining 
data depend heavily on the genetic distance between the populations that are used (Lund et al., 2014) as well as the similarity in trait definition.

Reproductive efficiency is of paramount importance for the dairy cattle industry worldwide. Female fertility traits have received much attention in the last 2 decades, and most countries now include them in the breeding goals and selection programs (Berry et al., 2014). On the other hand, bull fertility has been generally overlooked. Recent studies have reported promising results related to the feasibility of predicting dairy bull fertility using genomic data (Abdollahi-Arpanahi et al., 2017; Nani et al., 2019; Rezende et al., 2019; Pacheco et al., 2020). It should be noted that national dairy bull fertility evaluations are implemented in a few countries, including sire conception rate (SCR) in the United States and semen fertility value (SFV) in Australia (Carrick et al., 2000; Kuhn and Hutchison, 2008; Kuhn et al., 2008). Despite the importance of the Jersey breed in these 2 countries, the bull fertility data set available is comparatively small, even when considering the entire national historical data, which limits the implementation of genomic prediction for bull fertility. One way to increase the size of the reference data set would be to combine bull fertility records from both countries. In this scenario, it is expected that a joint reference population combining US and Australian (AU) Jersey bulls would increase the accuracy of genomic predictions for both populations.

To the best of our knowledge, this is the first study that has investigated the feasibility of genomic prediction of yet-to-be observed bull fertility performance using an across-country reference data set. Our first objective was to evaluate the genetic relatedness within and across US and AU Jersey populations. Given that the accuracy of genomic prediction is influenced not only by the size of the reference data set but also by the genetic relationships between reference and candidate animals, balancing the effects of both factors is important. Consequently, our second objective was to optimize the AU Jersey reference population to maximize the accuracy of genomic predictions. Finally, given that the AU and US Jersey data sets are relatively small, we investigated the prediction of unobserved SCR and SFV records using both univariate and bivariate genomic predictive models using a joint reference population combining AU and US Jersey records.

\section{MATERIALS AND METHODS}

\section{Phenotypic Data}

The US national dairy bull fertility evaluation (SCR) is provided by the Council on Dairy Cattle Breeding
(CDCB; Bowie, MD). The AU national dairy bull fertility (SFV) is provided by DataGene (Melbourne, Australia). Both evaluations of service sire fertility are intended as phenotypic rather than genetic evaluation, because the differences in fertility between bulls reflect both genetic and nongenetic effects. These evaluations use field data, either confirmed pregnancy records (SCR) or nonreturn to service records (SFV), to determine the conception rate of a bull, taking into account not only factors related to the sire under evaluation, but also factors associated with the cow that received the unit of semen (Carrick et al., 2000; Kuhn and Hutchison, 2008; Kuhn et al., 2008). Both SCR and $\mathrm{SFV}$ values are defined as the expected difference in conception rate of a given bull compared with the mean of all the bulls evaluated together.

Sire Conception Rate. A total of 1,570 US Jersey bulls with SCR from 29 consecutive evaluations performed between August 2008 and April 2018 were used in this study. For bulls with multiple evaluations, only the most reliable SCR value (i.e., the SCR record with most breedings), was included in the analyses. The Jersey SCR values ranged from -15.1 to +5.5 , and the number of breedings per bull ranged from 200 to 26,617 . The SCR records are freely available at the CDCB website (https://www.uscdcb.com/).

Semen Fertility Value. A total of 603 AU Jersey bulls with SFV records were used in this study. The SFV records were obtained from the July 2019 AU national evaluation conducted by DataGene Ltd. The SFV values ranged from -15.29 to +7.36 , and the number of breedings per bull ranged from 10 to 14,029. The SFV records from bulls with more than 400 matings are publicly available at the DataGene website (https:/ /datagene.com.au/node/1249).

A total of 167 Jersey bulls were evaluated in both countries and had both SCR and SFV records. The reliabilities of SCR and SFV values were calculated based on the number of breedings $(n)$; following $\mathrm{CDCB}$, reliability was calculated as $R E L=100 \times\left[\frac{n}{(n+260)}\right]$. Reliability values ranged from 43 to 99 for SCR, and from 4 to 98 for SFV.

\section{Genotypic Data}

The Cooperative Dairy DNA Repository provided 107,371 SNP data for all the Jersey bulls with SCR records and 108 Jersey bulls with SFV records. In addition, Agriculture Victoria provided 633,374 SNP data for 495 AU Jersey bulls with SFV records, imputed from 50,000 genotypes provided to DataGene by AI organizations (Erbe et al., 2012). A total of 96,147 SNP 
Table 1. Overview of the different scenarios, combining records from the United States (US) and Australia (AU)

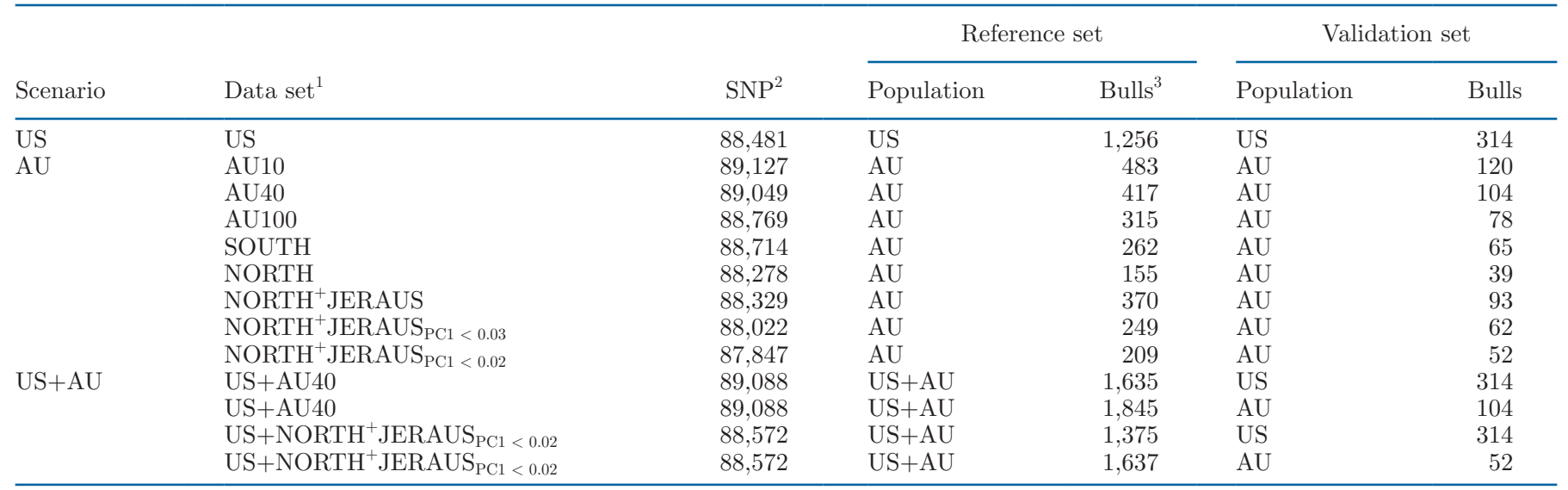

${ }^{1}$ AU10-100: subsets of bulls defined based on the minimum number of breedings needed to calculate semen fertility values (SFV). NORTH or SOUTH: subsets of bulls defined based on the hemisphere of origin. JERAUS: Australian Jersey bulls. PC1 < 0.02 or PC1 < 0.03 : subsets of bulls defined based on the first principal component of the $\mathbf{G}$ matrix.

${ }^{2} \mathrm{SNP}=$ number of SNP markers used in each scenario.

${ }^{3}$ Bulls $=$ number of bulls in each data set.

in common between the 2 genotype files were retained for subsequent analyses. Those markers that mapped to the sex chromosomes, had minor allelic frequency below $1 \%$, or call rate less than $90 \%$ were removed. After editing, the total number of markers used in the analyses varied from 88,022 to 89,127 , depending on the number of animals available.

\section{Assessment of Genomic Relatedness Across Populations}

Genomic relatedness within and across US and AU populations was evaluated using principal component analysis. All US and AU bulls with more than 40 breedings were used in this analysis. High linkage SNP markers were removed using the PLINK procedure indep-pairwise 100100.5 , where 100 is the number of SNP in the sliding window, 10 is the number of SNP to shift the window in each iteration, and 0.5 is the pairwise SNP-SNP genotypic correlation threshold (see further details at http://zzz.bwh.harvard.edu/plink/ summary.shtml). A total of 28,211 SNP passed the LDbased variant pruning and were used for the principal component analysis, which was performed based on the variance-standardized genomic relationship matrix using PLINK (Purcell et al., 2007).

\section{Genomic Prediction: Scenarios}

The accuracy of genomic prediction was evaluated in 3 different scenarios (Table 1). In the first scenario, within US genomic prediction, only US Jersey bulls were used as reference population to predict SCR values. In the second scenario, within AU genomic prediction, only AU Jersey bulls were used as reference population to predict SFV values. Different criteria were evaluated to define the $\mathrm{AU}$ reference population, including number of breedings and country of origin. In the third scenario, across-country genomic prediction, different approaches for combining US and AU (US+AU) records in the reference population were investigated, including the use of the entire AU bull population or only a subset of closely related animals.

\section{Genomic Prediction: Statistical Models}

Univariate genomic BLUP (GBLUP) models were implemented for within-country genomic prediction, either the United States or Australia, and also for acrosscountry genomic prediction using the US+AU reference population. The general equation for univariate models was:

$$
\mathbf{y}=\mathbf{X b}+\mathbf{Z u}+\mathbf{e}
$$

where $\mathbf{y}$ is the vector of phenotypic records, $\mathbf{X}$ is the incidence matrix linking the fixed effects to phenotypic records, $\mathbf{b}$ is the vector of fixed effects included in the model, $\mathbf{Z}$ is the incidence matrix relating animal effects to phenotypic records, $\mathbf{u}$ is the vector of random animal genetic effects, and $\mathbf{e}$ is the vector of random residual effects. The random components of the model, $\mathbf{u}$ and $\mathbf{e}$, were distributed as $\mathbf{u} \sim \mathrm{N}\left(0, \mathbf{G} \sigma_{\mathrm{u}}^{2}\right)$ and $\mathbf{e} \sim \mathrm{N}\left(0, \mathbf{R} \sigma_{\mathrm{e}}^{2}\right)$, 
where $\sigma_{\mathrm{u}}^{2}$ and $\sigma_{\mathrm{e}}^{2}$ are the genetic and residual variances, respectively, $\mathbf{G}$ is the genomic relationship matrix, and $\mathbf{R}$ is a diagonal matrix with its elements equaled $1 /$ $R E L$ (i.e., inverse of the reliability of the phenotypic records).

Alternatively, bull fertility records from the United States and Australia were considered as correlated traits, and the following bivariate GBLUP model was implemented for across-country genomic prediction:

$$
\left[\begin{array}{l}
\mathbf{y}_{1} \\
\mathbf{y}_{2}
\end{array}\right]=\left[\begin{array}{cc}
\mathbf{X}_{1} & 0 \\
0 & \mathbf{X}_{2}
\end{array}\right]\left[\begin{array}{l}
\mathbf{b}_{1} \\
\mathbf{b}_{2}
\end{array}\right]+\left[\begin{array}{cc}
\mathbf{Z}_{1} & 0 \\
0 & \mathbf{Z}_{2}
\end{array}\right]\left[\begin{array}{l}
\mathbf{u}_{1} \\
\mathbf{u}_{2}
\end{array}\right]+\left[\begin{array}{l}
\mathbf{e}_{1} \\
\mathbf{e}_{2}
\end{array}\right]
$$

where $\mathbf{y}_{1}$ and $\mathbf{y}_{2}$ are the vectors of bull fertility records, $\mathbf{X}_{1}$ and $\mathbf{X}_{2}$ are incidence matrices linking fixed effects to phenotypes, $\mathbf{b}_{1}$ and $\mathbf{b}_{2}$ are vectors of fixed effects, $\mathbf{Z}_{1}$ and $\mathbf{Z}_{2}$ are the incidence matrices relating animal effects to phenotypic records, $\mathbf{u}_{1}$ and $\mathbf{u}_{2}$ are the vectors of the random animal effects, and $\mathbf{e}_{1}$ and $\mathbf{e}_{2}$ are the vectors of random residual effects. It was assumed that $\left[\begin{array}{l}\mathbf{u}_{1} \\ \mathbf{u}_{2}\end{array}\right] \sim \operatorname{MVN}(0, \mathbf{G} \otimes \mathbf{T})$, where $\mathbf{T}=\left[\begin{array}{cc}\sigma_{\mathrm{u} 1}^{2} & \sigma_{\mathrm{u} 12} \\ \sigma_{\mathrm{u} 12} & \sigma_{\mathrm{u} 2}^{2}\end{array}\right]$ is the genetic variance-covariance matrix of $\mathbf{y}_{1}$ and $\mathbf{y}_{2}$, and $\left[\begin{array}{l}\mathbf{e}_{1} \\ \mathbf{e}_{2}\end{array}\right] \sim \operatorname{MVN}(0, \mathbf{R} \otimes \mathbf{E})$, where $\mathbf{E}=\left[\begin{array}{cc}\sigma_{\mathrm{e} 1}^{2} & 0 \\ 0 & \sigma_{\mathrm{e} 2}^{2}\end{array}\right]$ is the residual variance-covariance matrix of $\mathbf{y}_{1}$ and $\mathbf{y}_{2}$, and MVN represents the multivariate normal distribution.

Both univariate and bivariate GBLUP models were implemented using genomic relationship matrices $(\mathbf{G})$ constructed based on VanRaden (2008), assuming the allelic frequency of the current population:

$$
\mathbf{G}=0.99 \times \frac{\mathbf{Z Z}^{\prime}}{2 \times \sum \mathrm{p}_{\mathrm{i}}\left(1-\mathrm{p}_{\mathrm{i}}\right)}+0.01 \times \mathbf{I},
$$

where $\mathbf{Z}$ is a centered incidence matrix of genotype covariates $(0,1,2), 2 \times \Sigma \mathrm{p}_{\mathrm{i}}\left(1-\mathrm{p}_{\mathrm{i}}\right)$ is a scaling parameter in which $\mathrm{p}_{\mathrm{i}}$ and $\mathrm{q}_{\mathrm{i}}$ are the allelic frequencies for $i^{\text {th }} \mathrm{SNP}$, which were computed within each scenario, and $\mathbf{I}$ is an identity matrix. When the US and AU bulls were combined, the 2 populations were considered as one population in the construction of $\mathbf{G}$. The number of SNP used for constructing $\mathbf{G}$ and the number of bulls are shown in Table 1.

All these models were implemented using the BLUPf90 family of programs from Ignacy Misztal and collaborators, University of Georgia (http://nce .ads.uga.edu/software/). Variance-covariance matrices were estimated using airemlf90, and genomic prediction analyses were performed using blupf90.

\section{Genomic Prediction: Model Predictive Ability}

A 5-fold cross-validation approach was used to evaluate the ability of the alternative genomic models to predict yet-to-be observed bull fertility values. The corresponding data set (US, AU, or US+AU) was randomly split into 5 disjoint subsets of approximately the same size. In each iteration of the cross-validation, 4 of the 5 subsets were combined to become a reference set (train) to estimate the solutions of fixed and random effects, and the remaining set was used as validation set (test) to evaluate model predictive ability. For the across-country scenarios, a restriction was imposed that one-fifth of the US or AU bulls were included in the validation population.

The ability to predict yet-to-be observed bull fertility values was assessed using the Pearson product-moment correlation coefficient (CORR) and the mean squared error of prediction (MSEP). The correlation between observed bull fertility values $(y)$ and predicted bull fertility values $(\hat{y})$ and the MSEP, defined as the average of the squared differences between $y$ and $\hat{y}$, were calculated in each cross-validation testing fold. All the cross-validation procedures were repeated 10 times; therefore, the output of each analysis was the average of 50 estimates.

\section{RESULTS AND DISCUSSION}

Fertility is an important economic trait, and despite recent advances, the reproductive performance of dairy cattle remains suboptimal. Bull subfertility is often ignored as a potential cause of reproductive inefficiency. Dairy bull fertility is typically evaluated in the laboratory using different semen attributes, such as sperm motility and sperm concentration. In addition, bull fertility can be evaluated in the field using conception rate records. Indeed, few countries have developed dairy bull fertility evaluations using cow field data. These evaluations are time-consuming; only bulls that reach the market can be evaluated, and they should be in service for at least $1 \mathrm{yr}$ or until enough number of inseminations are carried out. Thus, limited data sets are available, especially for numerically small breeds, such as Jersey, inhibiting the implementation of genomic prediction. Within-breed across-country genomic prediction has the advantage of increasing the size of the reference population, which is expected to result in more accurate genomic predictions. This study was 
specially conducted to investigate the benefits of predicting dairy bull fertility using an across-country reference data set. We first evaluated the genetic relatedness within and across US and AU Jersey bull populations. Then, given that the AU population is genetically diverse, we optimized the AU reference population by including only closely related animals. Lastly, we investigated both within-country and across-country genomic prediction of bull fertility using either univariate or bivariate models fitting alternative training sets (i.e., using different combinations of $\mathrm{AU}$ and US records). The highest predictive performance for SFV values was obtained with a bivariate genomic model that used an across-country reference data set.

\section{Genetic Characterization of Jersey Bull Populations}

The first 2 principal components were plotted and annotated by population and country of origin to determine the genetic relatedness within and across US and AU Jersey bulls (Figure 1). Interestingly, US and AU bull populations showed some degree of differentiation (Figure 1C). The dissimilarity between US and some AU bulls was more evident when analyzing the country of origin of the bulls (Figure 1D).

The vast majority of the Jersey bulls with SCR records are originally from the United States, including JERUSA and JER840, representing $97 \%$ of the total US Jersey population. Few bulls from Canada (JERCAN; $\mathrm{n}=39$ ), Australia (JERAUS; $\mathrm{n}=4$ ), and Denmark (JERDNK; $\mathrm{n}=4$ ) also have SCR records, and they appear to be highly related to the American population. On the other hand, the set of bulls with SFV records represents a much more diverse population, including bulls originally from Australia (JERAUS, $\mathrm{n}=269$ ), the United States (JERUSA and JER840, $\mathrm{n}=164$ ), New Zealand (JERNZL, $\mathrm{n}=58$ ), Denmark (JERDNK, $\mathrm{n}$ $=15$ ), Canada (JERCAN, $\mathrm{n}=14$ ), and Great Britain (JERGBR, $\mathrm{n}=1$ ). In addition, within the JERAUS subset, some are more similar to bulls originally from the United States (JERUSA and JER840), whereas others are more similar to bulls from New Zealand (JERNZL).

Previous studies have consistently found that New Zealand (NZ) dairy cattle populations are genetically different from other dairy cattle populations, and $\mathrm{AU}$ dairy cattle populations appear to be a mix of US and NZ populations (de Roos et al., 2008; Tyrisevä et al., 2011; Pryce et al., 2012; Pryce et al., 2014; Howard et al., 2015). One reason for this could be the limited degree of genetic material exchange across North America, Australia, and New Zealand (de Roos et al., 2008). Moreover, differences in the relative importance of a given trait across breeding programs, and differences in environmental and management conditions where animals perform, may lead to small differences in allelic frequencies across populations of the same breed due to different selection pressures across the genome. In fact, Howard et al. (2015) reported multiple regions of the genome undergoing different directional selection across US, AU, and NZ Jersey cow and bull populations. Furthermore, it is known that the NZ Holstein population is an admixture of cattle of New Zealand and North American ancestry that was graded up from Jerseys (Harris and Kolver, 2001). Likewise, an admixture breeding that may include crossbreeding with other dairy breeds could also have been responsible for the genetic differentiation of JERNZL bulls. Crossbreeding in dairy cattle including use of crossbred bulls for AI is commonly practiced in New Zealand.

Overall, our results suggest higher genetic similarity within the US Jersey population than within the AU Jersey population. Notably, bulls with SFV records originally from the northern hemisphere (NORTH; n $=194$ ), including JERUSA, JER840, JERDNK, JERCAN, JERGBR, are more genetically related to each other than those bulls from the southern hemisphere (SOUTH; $\mathrm{n}=327$ ), namely JERAUS and JERNZL. Our findings provide further evidence that the AU dairy cattle population is a mix of US and NZ populations, and that the NZ population has a particular genetic background.

\section{Within-Country Genomic Prediction}

Given the population structure of the AU population, alternative subsets of AU bulls were evaluated to optimize the reference population, and hence, maximize the accuracy of genomic predictions of SFV values. Model predictive ability was evaluated using 5-fold cross-validation repeated 10 times, so each analysis resulted in 50 estimates of predictive correlation and MSEP (Figure 2).

On the one hand, the reliability of the bull fertility estimates depends heavily on the number of breedings used for the evaluation, and as expected, those bulls with hundreds or thousands of breedings have more reliable SFV records. In fact, AU Jersey bulls with fewer than 40 or 100 breedings had reliability values up to 13 or $27 \%$, respectively. On the other hand, increasing the minimum number of breedings limits the number of available animals in the reference population. For instance, a total of 603,521 , and 393 Jersey bulls had SFV records calculated using at least 10 (AU10), 40 (AU40), and 100 (AU100) breedings, respectively. Therefore, we investigated the predictive ability of 
Population - US ^ $\mathrm{AU} *$ Both

Origin • JER840 • JERAUS • JERCAN

JERDNK • JERGBR ・ JERNZL • JERUSA

A
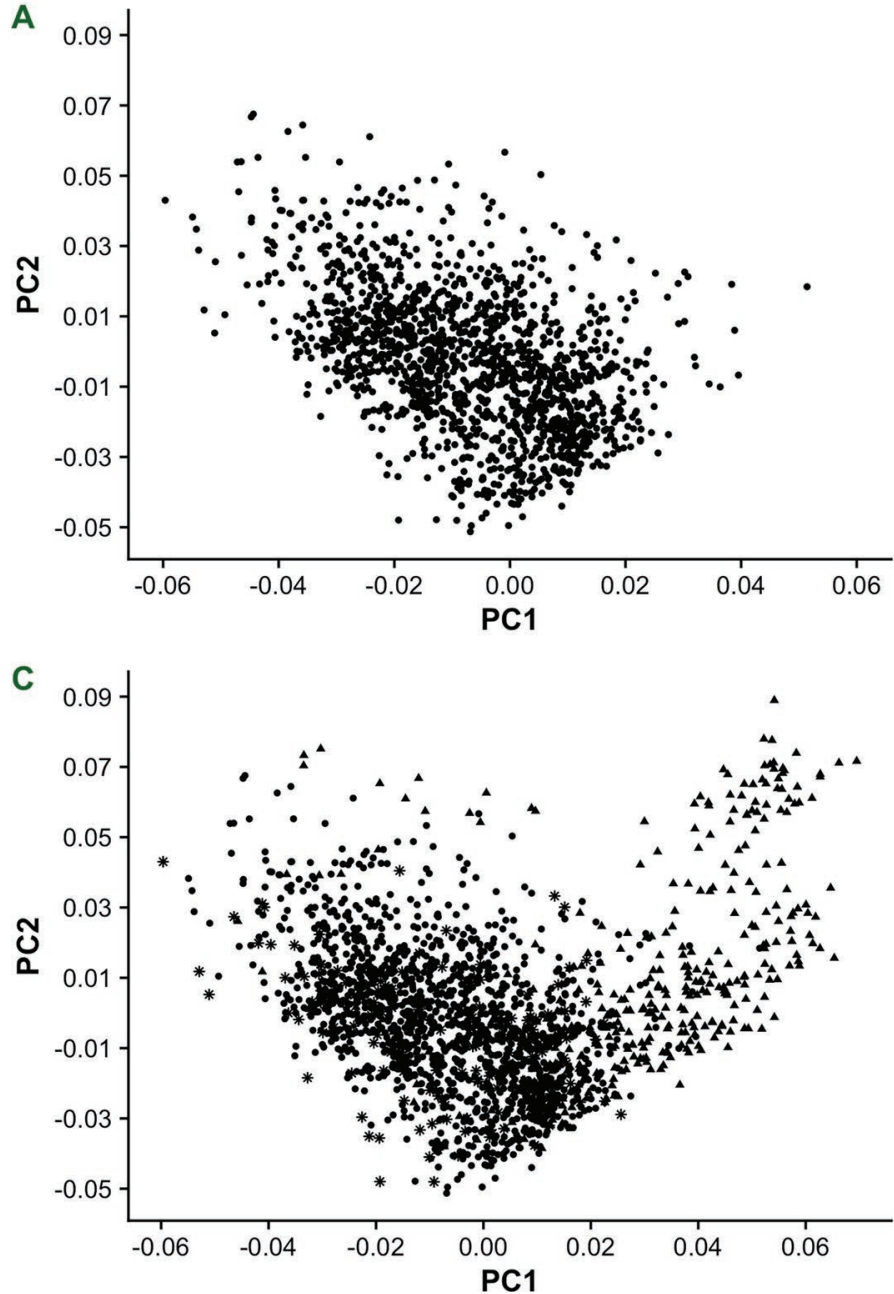

B
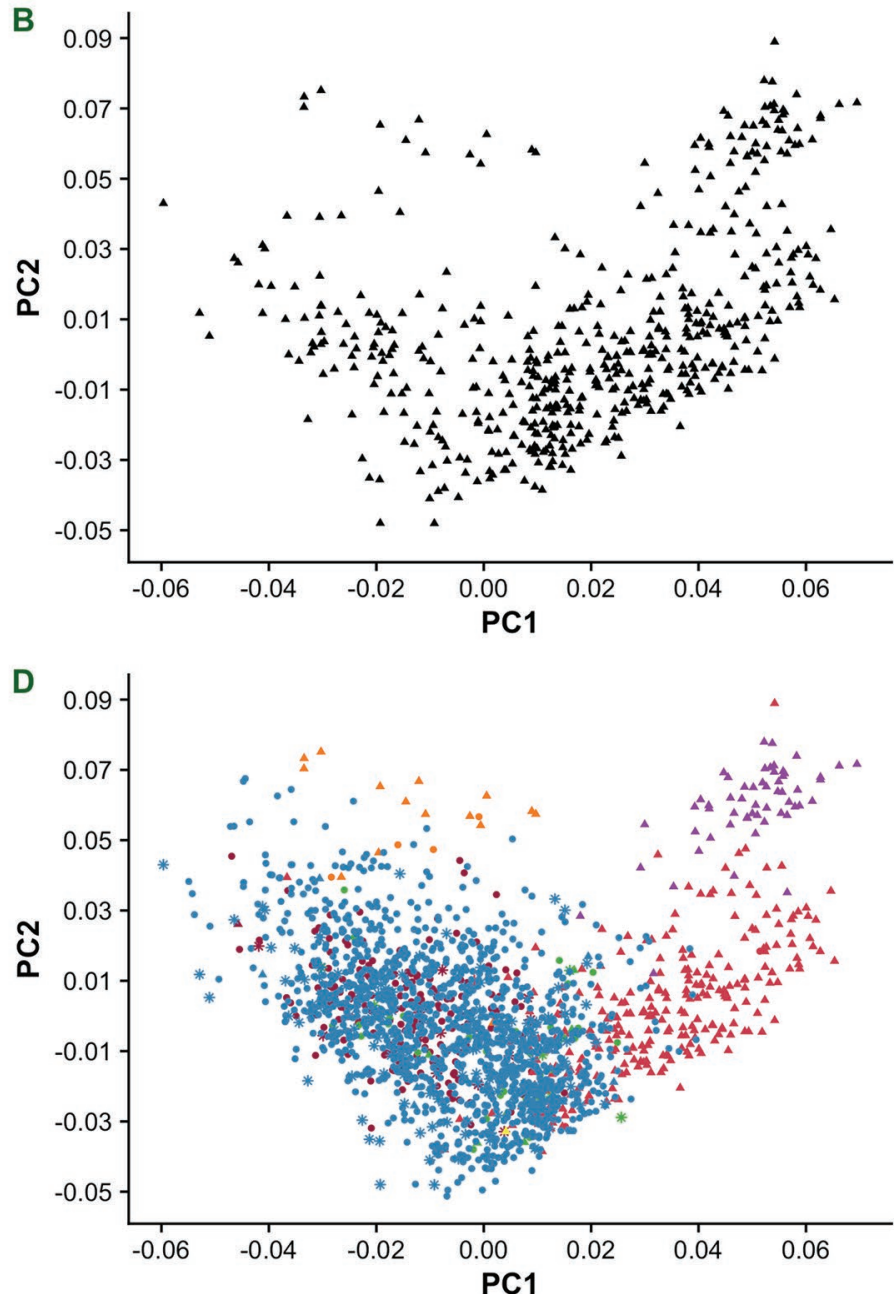

Figure 1. Assessment of genomic relatedness based on the first 2 principal components (PC) of the genomic relationship matrix. (A) US Jersey population (bulls with SCR records); (B) Australian Jersey population (bulls with SFV records); (C) both US and Australian Jersey populations, highlighting bulls with SCR (dot), SFV (triangle), or both records (star); (D) US and Australian Jersey populations based on the country of origin of each bull, United States (JER840 and JERUSA), Australia (JERAUS), Canada (JERCAN), Denmark (JERDNK), Great Britain (JERGBR), and New Zealand (JERNZL).

genomic models fitting different subsets, from AU10 to AU100 (i.e., subsets of bulls defined based on the minimum number of breedings needed to calculate SFV values; Figure 2, light blue boxplots). Notably, both higher average predictive correlation and lower average MSEP were achieved when bulls with at least 40 breedings were considered $(\mathrm{CORR}=0.09$ and $\mathrm{MSEP}=7.66)$ compared with at least $10(\mathrm{CORR}=0.02$ and MSEP $=$ $8.50)$ or at least $100(\mathrm{CORR}=0.06$ and $\mathrm{MSEP}=8.76)$ breedings. Therefore, just maximizing the size of the reference population (AU10) did not result in increased reliability. Both balancing size and using reliable phenotypes (AU40) are important.
It is well established that the performance of genomic prediction is strongly affected by the genetic relatedness between candidate animals and the reference population (Habier et al., 2010; Pszczola et al., 2012; Wientjes et al., 2013). Here, we evaluated the predictive performance of genomic models fitting different AU40 subsets, namely NORTH or SOUTH (i.e., subsets of bulls defined based on the hemisphere of origin). The NORTH subpopulation showed a greater genetic similarity than the SOUTH subpopulation, and this was reflected in the predictive performance, models fitting the NORTH subset showed higher predictive correlation (0.18 vs. 0.02 ) and lower MSEP (5.99 vs. 8.76) 

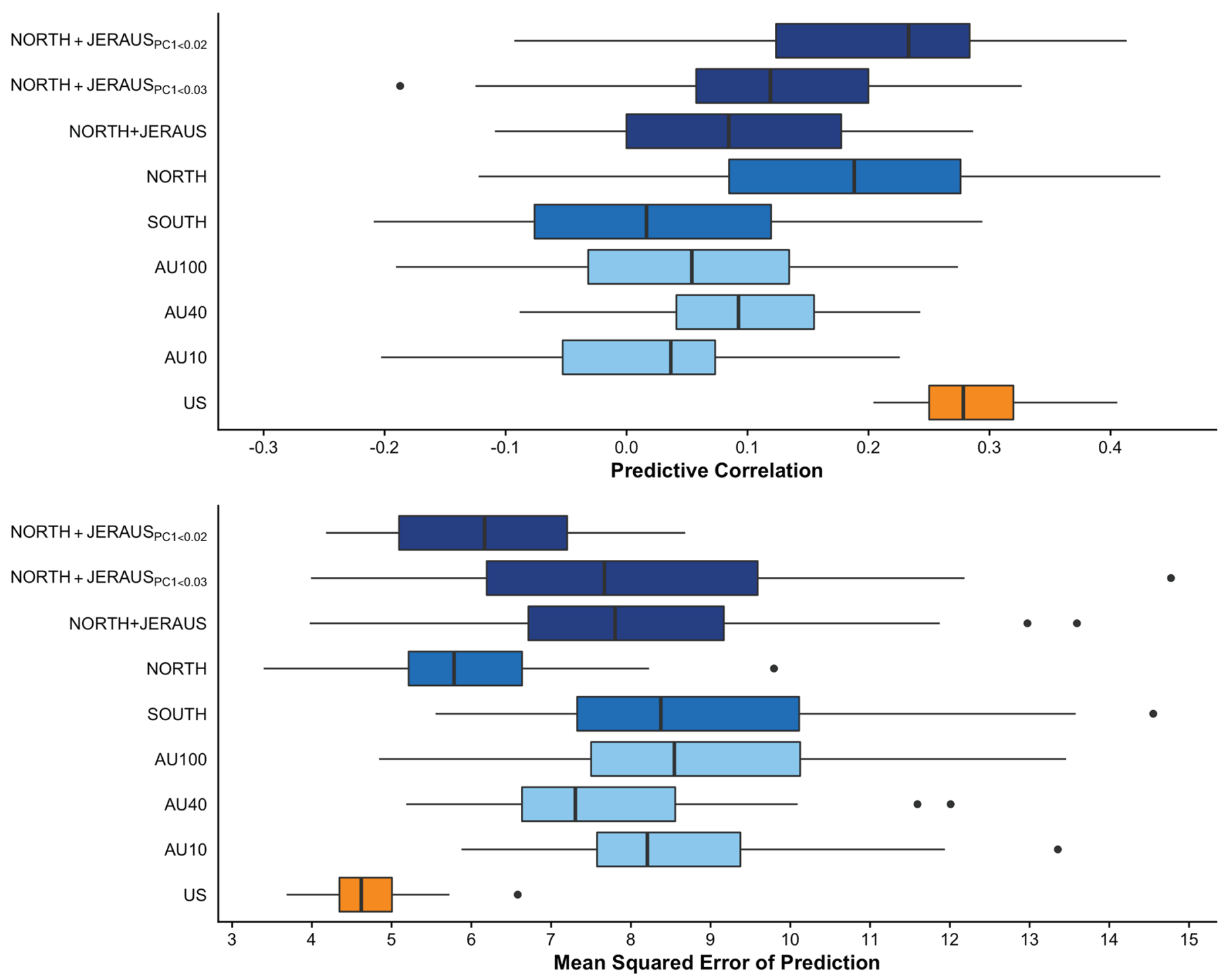

Figure 2. Within-country genomic prediction of SFV and SCR records. Predictive correlation (top) and mean squared error of prediction (below) were calculated using 5-fold cross-validation with 10 replicates. Predictions were performed using univariate genomic BLUP models fitting the entire US Jersey population (orange) or subsets of Australian Jersey bulls defined based on (1) minimum number of breedings (10, 40, or 100; light blue), (2) hemisphere of origin (NORTH or SOUTH; intermediate blue), or (3) relatedness between individuals based on the first principal component of the $\mathbf{G}$ matrix $(\mathrm{PC} 1<0.02$ or $\mathrm{PC} 1<0.03$; dark blue).

than models fitting the SOUTH subset (Figure 2, blue boxplots). Of interest, compared with the entire AU40 subset, the NORTH subpopulation doubled the predictive correlation (0.18 vs. 0.09$)$ and decreased $22 \%$ the MSEP (5.99 vs. 7.66$)$.

Finally, we evaluated the benefits of incorporating all or at least some of the JERAUS bulls (Jersey bulls originally from Australia) into the NORTH subset. Three alternative scenarios were evaluated: adding all the JERAUS bulls (NORTH+JERAUS, $\mathrm{n}=463$ ) or adding only those JERAUS bulls more closely related to the NORTH subpopulation based on the first principal component $\left(\mathrm{NORTH}+\mathrm{JERAUS}_{\mathrm{PC} 1}<0.02, \mathrm{n}\right.$
$=261$ or NORTH $+\mathrm{JERAUS}_{\mathrm{PC} 1<0.03}, \mathrm{n}=311$ ). The best predictive performance was achieved by fitting the $\mathrm{NORTH}+$ JERAUS $\mathrm{PC1}_{20.02}$ subset, both in terms of the highest predictive correlation $(0.20)$ and the lowest MSEP (6.27; Figure 2, dark blue boxplots). Although larger reference populations generally result in more accurate genomic predictions within breed (Goddard and Hayes, 2009), our results indicate that the largest training set is not always better than a smaller set, but more reliable and closer genetically related subpopulation.

We also evaluated the genomic prediction of Jersey SCR values using a within-country approach. The av- 
erage predictive correlation was 0.28 and the average MSEP was 4.71 fitting a univariate GBLUP model using only US Jersey records (Figure 2, orange boxplot). Rezende et al. (2019) reported very similar results $(\mathrm{CORR}=0.29$ and MSEP $=4.68)$ using an equivalent genomic prediction model (a linear kernel-model) fitting 95,434 SNP and 1,569 bulls.

\section{Across-Country Genomic Prediction}

The prediction of yet-to-be observed SFV values was evaluated using both univariate and bivariate models fitting different US+AU data sets (Figure 3). Combining all SCR records with SFV records with more than 40 breedings (US+AU40) resulted in lower predictive ability than using only the AU40 subset, regardless of the model used (Figure 3, light green boxplots). Indeed, the AU40 subset achieved CORR of 0.09 and MSEP of 7.66, whereas univariate and bivariate models fitting the US+AU40 data set yielded average predictive correlations between 0.07 and 0.04 , and average MSEP between 7.90 and 8.41. These findings could be explained by the presence of JERNLZ bulls and some JERAUS bulls in the AU40 subset that are genetically distant from the US Jersey population.

Adding the entire US Jersey SCR data set into the optimized AU Jersey reference population, namely $\mathrm{US}+\mathrm{NORTH}+\mathrm{JERAUS}_{\mathrm{PC} 1<0.02}$, did not improve the prediction of SFV values when a univariate model was used (Figure 3, dark green boxplots). However, the bivariate model fitting US and NORTH+JERAUS $\mathrm{PC1}_{\mathrm{PC}<02}$ data sets achieved a better predictive correlation $(0.24$ vs. 0.20) than the univariate model fitting only

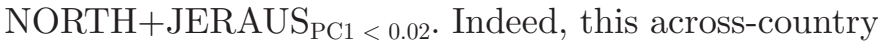
bivariate model exhibited the best performance for predicting yet-to-be observed SFV values. The superiority of the bivariate model can be explained by the fact that US and AU bull fertility evaluations have slight differences, such as type of cow field data used and the variables accounted in the evaluation model, as well as the terms included in the bull fertility estimates (Carrick et al., 2000, Kuhn and Hutchison, 2008, Kuhn et al., 2008). The US dairy bull fertility evaluation uses confirmed pregnancy records, whereas the AU evaluation is based on nonreturn to service records. In addition, the US evaluation model incorporates lactation
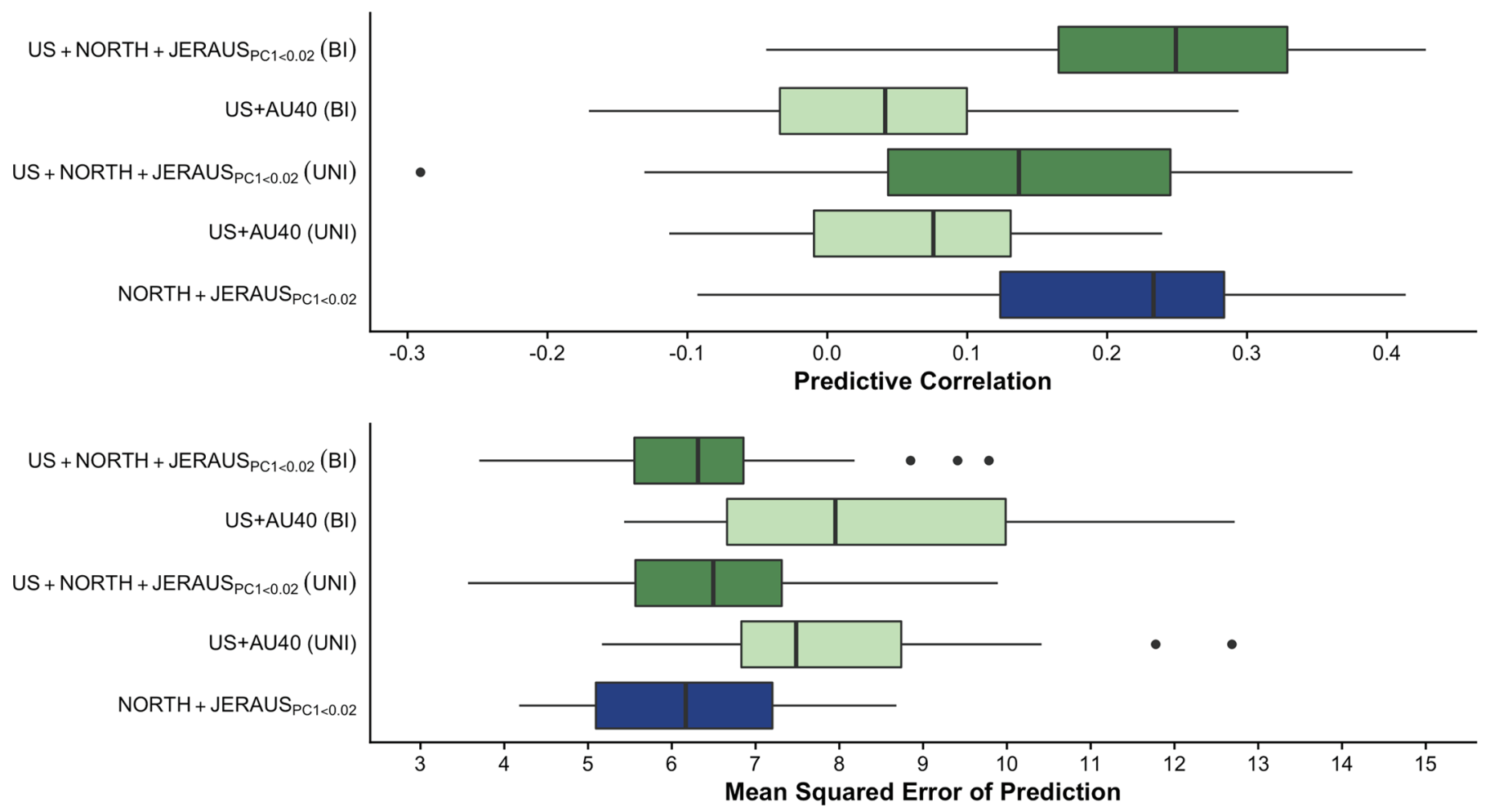

Figure 3. Across-country genomic prediction of SFV records using alternative combinations of US and Australian (US+AU) data sets. Predictive correlation (top) and mean squared error of prediction (below) were calculated using 5 -fold cross-validation with 10 replicates. Predictions were performed using univariate (UNI) and bivariate (BI) genomic BLUP models fitting all US Jersey data plus Australian bulls with more than 40 breedings (US+AU40; light green) or all US Jersey data plus an optimized Australian Jersey reference set $\left(\mathrm{US}^{+} \mathrm{NORTH}^{+} \mathrm{JERAUS} \mathrm{PC}_{2}<0.02\right.$; dark green). 
number and milk yield as nuisance variables. Lastly, the SCR value is an expanded service sire term that includes not only the sire effect, but also age and inbreeding of the sire, and stud $\times$ year effect. In fact, SCR and SFV are not the same trait but are moderately correlated (genetic correlation $=0.49$ ), which explains the better performance of the bivariate model compared with the univariate model for the genomic prediction of unobserved SFV values. Overall, we achieved a remarkable improvement on the ability to predict SFV records, from using all AU records to only AU40, then NORTH+JERAUS $\mathrm{PC1}_{20.02}$, and finally US+NORTH+JERAUS $\mathrm{PC} 1<0.02$.

We also evaluated the benefits of using SFV records to predict future SCR values. Neither univariate nor bivariate models fitting US+AU40 or US+NORTH+JERAUS ${ }_{\mathrm{PC} 1<0.02}$ data sets outperformed the within-country approach (i.e., a model fitting a pure US Jersey reference population; data not shown). Therefore, the addition of up to 379 new bull fertility records to the US data set was not enough to improve the genomic predictions of SCR values.

\section{CONCLUSIONS}

Our findings reinforce the idea that genomic prediction of bull fertility is feasible in dairy cattle. Note that SCR and SFV records are available only after the bulls are in the market, and hence, early genomic predictions can help the dairy industry make accurate genomeguided selection decisions, such as early culling of predicted subfertile bull calves. Given that the AU Jersey bull population is quite diverse, balancing the size of the reference population and relatedness between reference and candidate animals is of paramount importance to obtain more accurate genomic predictions of bull fertility. The highest predictive performance for SFV values was obtained with a bivariate genomic model that used an across-country reference data set. On the other hand, there was no advantage of combining US and AU records for the genomic prediction of SCR values. Future endeavors should explore the use of even more records to expand current training sets. In this sense, other countries have similar national field evaluations of bull fertility, such as Canada and Denmark, and also most breeding companies run internal analyses for bull fertility. Therefore, the use of these resources might provide new opportunities for the genomic prediction of both SFV and SCR records in Jersey dairy cattle.

\section{ACKNOWLEDGMENTS}

This study was funded by the American Jersey Cattle Club Research Foundation. The authors thank the Cooperative Dairy DNA Repository, the Council on Dairy Cattle Breeding and DataGene for providing the genotypic and phenotypic data. The authors have not stated any conflicts of interest.

\section{REFERENCES}

Abdollahi-Arpanahi, R., G. Morota, and F. Peñagaricano. 2017. Predicting bull fertility using genomic data and biological information. J. Dairy Sci. 100:9656-9666. https://doi.org/10.3168/jds .2017-13288.

Berry, D. P., E. Wall, and J. E. Pryce. 2014. Genetics and genomics of reproductive performance in dairy and beef cattle. Animal 8(Suppl. 1):105-121. https://doi.org/10.1017/S1751731114000743.

Brøndum, R. F., E. Rius-Vilarrasa, I. Strandén, G. Su, B. Guldbrandtsen, W. F. Fikse, and M. S. Lund. 2011. Reliabilities of genomic prediction using combined reference data of the Nordic Red dairy cattle populations. J. Dairy Sci. 94:4700-4707. https://doi.org/10 $.3168 /$ jds.2010-3765.

Carrick, M., M. E. Goddard, and P. J. Bowman. 2000. Evaluation of bull fertility using field data (corrected NRR and CCR). Pilot system for routine collation of non-return data for bulls. Pages 9-24 in Predicting and Monitoring the Fertility of Artificial Insemination Sires. The University of Queensland, Brisbane, Australia.

Daetwyler, H. D., B. Villanueva, and J. A. Woolliams. 2008. Accuracy of predicting the genetic risk of disease using a genome-wide approach. PLoS One 3:e3395. https://doi.org/10.1371/journal.pone .0003395 .

de Roos, A. P. W., B. J. Hayes, and M. E. Goddard. 2009. Reliability of genomic predictions across multiple populations. Genetics 183:1545-1553. https://doi.org/10.1534/genetics.109.104935.

de Roos, A. P. W., B. J. Hayes, R. J. Spelman, and M. E. Goddard. 2008. Linkage disequilibrium and persistence of phase in HolsteinFriesian, Jersey and Angus cattle. Genetics 179:1503-1512. https: //doi.org/10.1534/genetics.107.084301.

Erbe, M., B. J. Hayes, L. K. Matukumalli, S. Goswami, P. J. Bowman, C. M. Reich, B. A. Mason, and M. E. Goddard. 2012. Improving accuracy of genomic predictions within and between dairy cattle breeds with imputed high-density single nucleotide polymorphism panels. J. Dairy Sci. 95:4114-4129. https://doi.org/10.3168/jds .2011-5019.

Gebreyesus, G., H. Bovenhuis, M. S. Lund, N. A. Poulsen, D. Sun, and B. Buitenhuis. 2019. Reliability of genomic prediction for milk fatty acid composition by using a multi-population reference and incorporating GWAS results. Genet. Sel. Evol. 51:16. https://doi .org/10.1186/s12711-019-0460-z.

Goddard, M. 2009. Genomic selection: Prediction of accuracy and maximisation of long term response. Genetica 136:245-257. https: //doi.org/10.1007/s10709-008-9308-0.

Goddard, M. E., and B. J. Hayes. 2009. Mapping genes for complex traits in domestic animals and their use in breeding programmes. Nat. Rev. Genet. 10:381-391. https://doi.org/10.1038/nrg2575.

Habier, D., J. Tetens, F.-R. Seefried, P. Lichtner, and G. Thaller. 2010. The impact of genetic relationship information on genomic breeding values in German Holstein cattle. Genet. Sel. Evol. 42:5. https: //doi.org/10.1186/1297-9686-42-5.

Haile-Mariam, M., J. E. Pryce, C. Schrooten, and B. J. Hayes. 2015. Including overseas performance information in genomic evaluations of Australian dairy cattle. J. Dairy Sci. 98:3443-3459. https: //doi.org/10.3168/jds.2014-8785.

Harris, B. L., and E. S. Kolver. 2001. Review of Holsteinization on intensive pastoral dairy farming in New Zealand. J. Dairy Sci. 84:E56-E61. https://doi.org/10.3168/jds.S0022-0302(01)70197-X.

Hayes, B. J., P. J. Bowman, A. J. Chamberlain, and M. E. Goddard. 2009. Invited review: Genomic selection in dairy cattle: Progress and challenges. J. Dairy Sci. 92:433-443. https://doi.org/10.3168/ jds.2008-1646.

Howard, J. T., C. Maltecca, M. Haile-Mariam, B. J. Hayes, and J. E. Pryce. 2015. Characterizing homozygosity across United States, 
New Zealand and Australian Jersey cow and bull populations. BMC Genomics 16:187. https://doi.org/10.1186/s12864-015-1352 -4 .

Kuhn, M. T., and J. L. Hutchison. 2008. Prediction of dairy bull fertility from field data: Use of multiple services and identification and utilization of factors affecting bull fertility. J. Dairy Sci. 91:24812492. https://doi.org/10.3168/jds.2007-0743.

Kuhn, M., J. Hutchison, and H. Norman. 2008. Modeling nuisance variables for prediction of service sire fertility. J. Dairy Sci. 91:2823-2835. https://doi.org/10.3168/jds.2007-0946.

Liu, Z., F. R. Seefried, F. Reinhardt, S. Rensing, G. Thaller, and R. Reents. 2011. Impacts of both reference population size and inclusion of a residual polygenic effect on the accuracy of genomic prediction. Genet. Sel. Evol. 43:19. https://doi.org/10.1186/1297 $-9686-43-19$

Lund, M. S., A. P. W. de Roos, A. G. de Vries, T. Druet, V. Ducrocq, S. Fritz, F. Guillaume, B. Guldbrandtsen, Z. Liu, R. Reents, C. Schrooten, F. Seefried, and G. Su. 2011. A common reference population from four European Holstein populations increases reliability of genomic predictions. Genet. Sel. Evol. 43:43. https://doi .org/10.1186/1297-9686-43-43.

Lund, M. S., G. Su, L. Janss, B. Guldbrandtsen, and R. F. Brøndum. 2014. Genomic evaluation of cattle in a multi-breed context. Livest. Sci. 166:101-110. https://doi.org/10.1016/j.livsci.2014.05.008.

Nani, J. P., F. M. Rezende, and F. Peñagaricano. 2019. Predicting male fertility in dairy cattle using markers with large effect and functional annotation data. BMC Genomics 20:258. https://doi .org/10.1186/s12864-019-5644-y.

Pacheco, H. A., F. M. Rezende, and F. Peñagaricano. 2020. Gene mapping and genomic prediction of bull fertility using sex chromosome markers. J. Dairy Sci. 103:3304-3311. https://doi.org/10.3168/jds 2019-17767.

Pryce, J. E., J. Arias, P. J. Bowman, S. R. Davis, K. A. Macdonald, G. C. Waghorn, W. J. Wales, Y. J. Williams, R. J. Spelman, and B. J. Hayes. 2012. Accuracy of genomic predictions of residual feed intake and 250-day body weight in growing heifers using 625,000 single nucleotide polymorphism markers. J. Dairy Sci. 95:21082119. https://doi.org/10.3168/jds.2011-4628.

Pryce, J. E., J. Johnston, B. J. Hayes, G. Sahana, K. A. Weigel, S. McParland, D. Spurlock, N. Krattenmacher, R. J. Spelman, E. Wall, and M. P. L. Calus. 2014. Imputation of genotypes from low density (50,000 markers) to high density (700,000 markers) of cows from research herds in Europe, North America, and Australasia using 2 reference populations. J. Dairy Sci. 97:1799-1811. https:// doi.org/10.3168/jds.2013-7368.

Pszczola, M., T. Strabel, H. A. Mulder, and M. P. L. Calus. 2012. Reliability of direct genomic values for animals with different relationships within and to the reference population. J. Dairy Sci. 95:389-400. https://doi.org/10.3168/jds.2011-4338.
Purcell, S., B. Neale, K. Todd-Brown, L. Thomas, M. A. R. Ferreira, D. Bender, J. Maller, P. Sklar, P. I. W. de Bakker, M. J. Daly, and P. C. Sham. 2007. PLINK: A tool set for whole-genome association and population-based linkage analyses. Am. J. Hum. Genet. 81:559-575. https://doi.org/10.1086/519795.

Rezende, F. M., J. P. Nani, and F. Peñagaricano. 2019. Genomic prediction of bull fertility in US Jersey dairy cattle. J. Dairy Sci. 102:3230-3240. https://doi.org/10.3168/jds.2018-15810.

Su, G., P. Ma, U. S. Nielsen, G. P. Aamand, and G. Wiggans. 2016. Sharing reference data and including cows in the reference population improve genomic predictions in Danish Jersey. Animal 10:1067-1075. https://doi.org/10.1017/S1751731115001792.

Thomasen, J. R., C. Egger-Danner, A. Willam, B. Guldbrandtsen, M. S. Lund, and A. C. Sørensen. 2014. Genomic selection strategies in a small dairy cattle population evaluated for genetic gain and profit. J. Dairy Sci. 97:458-470. https://doi.org/10.3168/jds.2013 $-6599$.

Tyrisevä, A.-M., K. Meyer, W. F. Fikse, V. Ducrocq, J. Jakobsen, M. H. Lidauer, and E. A. Mäntysaari. 2011. Principal component approach in variance component estimation for international sire evaluation. Genet. Sel. Evol. 43:21. https://doi.org/10.1186/1297 -9686-43-21.

VanRaden, P. M. 2008. Efficient methods to compute genomic predictions. J. Dairy Sci. 91:4414-4423. https://doi.org/10.3168/jds .2007-0980.

VanRaden, P. M., C. P. Van Tassell, G. R. Wiggans, T. S. Sonstegard, R. D. Schnabel, J. F. Taylor, and F. S. Schenkel. 2009. Invited review: Reliability of genomic predictions for North American Holstein bulls. J. Dairy Sci. 92:16-24.

Weller, J. I., E. Ezra, and M. Ron. 2017. Invited review: A perspective on the future of genomic selection in dairy cattle. J. Dairy Sci. 100:8633-8644. https://doi.org/10.3168/jds.2017-12879.

Wientjes, Y. C. J., R. F. Veerkamp, and M. P. L. Calus. 2013. The effect of linkage disequilibrium and family relationships on the reliability of genomic prediction. Genetics 193:621-631. https:// doi.org/10.1534/genetics.112.146290.

Zhou, L., B. Heringstad, G. Su, B. Guldbrandtsen, T. H. E. Meuwissen, M. Svendsen, H. Grove, U. S. Nielsen, and M. S. Lund. 2014. Genomic predictions based on a joint reference population for the Nordic Red cattle breeds. J. Dairy Sci. 97:4485-4496. https://doi .org/10.3168/jds.2013-7580.

\section{ORCIDS}

Fernanda M. Rezende ํ https://orcid.org/0000-0002-0556-0192 Mekonnen Haile-Mariam (® https://orcid.org/0000-0001-5476-7475 Jennie E. Pryce (ㄴ) https://orcid.org/0000-0002-1397-1282 Francisco Peñagaricano () https://orcid.org/0000-0001-6661-3991 